\title{
DA GEOGRAFIA DA POPULAÇÃO À NECROPOLÍTICA: PRESENTIFICAÇÃO E DISPUTAS DE SENTIDO EM TEMPOS DE CORONAVÍRUS
}

\section{From the geography of the population to the necropolitics: presentness and disputes of meaning in times of coronavirus}

\author{
Eduardo Karol \\ Professor Adjunto do DGEO/FFP/UERJ \\ eduardokarol01@gmail.com \\ Catia Antonia da Silva \\ Professora Titular do DGEO/FFP/UERJ \\ catia.antonia@gmail.com
}

Artigo enviado para publicação em 21/04/2020 e aceito em 23/04/2020

DOI: $10.12957 /$ tamoios.2020.50375

\begin{abstract}
Resumo
O presente artigo tem como desafio analisar o contexto da crise do coronavírus na produção de discursos que fortalecem o pensamento da Necropolítica. A crise da COVID-19 é planetária. Começou na China e rapidamente se difundiu por mais de 180 países, devido à aceleração da circulação de pessoas na escala mundo. Assim, essa crise ganha a dimensão demográfica que merece reflexão geográfica e, sobretudo, a compreensão das narrativas que reafirmam a dimensão políticoconservadora que considera a mortalidade da população pobre e negra como positiva para a regulação da economia e superação das desigualdades sociais. Trata-se de um contexto em que a crise acelera a agudização das desigualdades e as formulações de superação de problemas ganham a dimensão de discursos genocidas e de perversidade que põem em xeque os limites da modernidade e da pauta humanista. Assim, mais uma vez a questão demográfica pode ganhar centralidade nesse debate pautado na superação das desigualdades pela negação do outro e pela destruição dos pobres. $\mathrm{O}$ artigo divide-se em duas seções: a primeira apresenta os dados disponíveis sobre a expansão do coronavírus e a segunda analisa a bibliografia que alimenta a necropolítica demográfica.
\end{abstract}

Palavras-chave: COVID-19; população; Geografia; necropolítica; Pandemia.

\begin{abstract}
The challenge of this article is to analyze the context of the coronavirus crisis in the production of speeches that strengthen the thinking of the Necropolitics. The COVID-19 crisis is planetary. It started in China and quickly spread to more than 180 countries, due to the accelerated movement of people on a world scale. Thus, this crisis gains a demographic dimension that deserves geographical reflection and, above all, an understanding of the narratives that reaffirm the political-conservative dimension that link the mortality of the poor and black population as positive for the regulation of the economy and overcoming social inequalities. It is a context in which the crisis accelerates the aggravation of inequalities and formulations to overcome problems take on the dimension of genocidal and perversity discourses that call into question the limits of modernity and the humanist agenda. Thus, once again the demographic issue can gain centrality in this debate based on overcoming inequalities by denying the other and destroying the poor. The article is divided into two sections: the first presents the available data on the expansion of the coronavirus and the second analyzes the bibliographic review that feeds the demographic necropolitics
\end{abstract}

Keywords: COVID-19; population; Geography; necropolitics; pandemic. 


\section{Introdução}

Impossível não refletir sobre o presente. Afinal, de que presente estamos falando? Quando se falou da expansão planetária de um vírus, sempre se imaginou que ele seria seletivo ou que demoraria a chegar. Mas qual é a surpresa? Afinal o vírus circula na velocidade da globalização. Milton Santos (1996) já chamava a atenção de que mundialização é diferente de globalização. O que marca a globalização é a velocidade da circulação na escala mundo e a simultaneidade dos eventos. Até então discutíamos no campo da Geografia, nos debates sobre economia, sobre a difusão do marketing, das cidades mundiais, da circulação de pessoas, que seja, em condição de refugiados, de turistas, de circuitos produtivos e de redes técnicas de comunicação e informação. Certamente no campo da epidemiologia, os especialistas já apontavam para a circulação planetária de vírus: a influenza em 1918 vitimou entre 25 a 50 milhões de pessoas em diversos lugares do mundo, noventa anos depois foi a H1N1 (gripe suína) a acometer muitos, e não podemos esquecer do vírus HIV, Síndrome da Imunodeficiência Humana Adquirida (SIDA em português) que circulou matando muitos e muitas em várias classes sociais e assim por diante. O que há de novo na COVID-19 revelada, na China, em 2019? O que há de novo é a capacidade rápida de difusão de acordo com a lógica de circulação do capitalismo globalizado. A segunda novidade é que a sua velocidade e a sua letalidade não ocorrem somente em um grupo social específico, ou em um espaço específico, como aconteceu com o ebola. Afinal, assim como em 1918, a chamada crise espanhola advinda da primeira Guerra Mundial se alastrou por boa parte do Mundo e obrigou a ações sanitaristas por parte do Estado e dos médicos da época, a COVID 19 tem semelhanças e diferenças. A semelhança é que como todo vírus novo, sua alta letalidade mobiliza a equipe médica a propor políticas sanitárias em caráter socialmente coercitivo, incluindo já naquela época os meios de comunicação (jornais impressos e rádio). O novo se refere àquilo que Santos vai chamar da constituição do espaço geográfico como meio técnico científico informacional. Ou seja, a informação em tempo real permitida pela infraestrutura de satélites, redes sociais, grandes empresas no setor de mídia para produzir a instantaneidade, por isso a percepção de que os impactos na economia serão grandes, exatamente e primeiramente porque as bolsas de valores trabalham com a mesma simultaneidade. No entanto, esse artigo tem como desafio analisar o contexto da crise do coronavírus na produção de discursos que fortalecem o pensamento da Necropolítica. Neste contexto de disputa entre economia, riqueza, necessidades e população, os estudos 
$\overline{\text { demográficos e da Geografia da população apontavam e em muitos casos faziam a }}$ proposição de solução da desigualdade social por meio da implementação da política de controle da população. Essa pauta tem retornado fortemente em diversas conjunturas e espaços, inclusive nos Estados Unidos da América que atualmente é o centro da Pandemia com maior números de infectados e de mortos, ultrapassando a Itália e Espanha.

As teorias demográficas de controle da população emergem no século XIX e Marx, já havia problematizado esse assunto, quando analisou a tese de Malthus sobre a necessidade do controle da natalidade para resolver os problemas das desigualdades sociais. Malthus ressaltou a importância do controle da natalidade para reduzir o crescimento populacional. Em sua teoria o crescimento populacional seria geométrico enquanto o crescimento dos alimentos seria aritmético, o que ocasionaria uma falta de alimentos no futuro, sua proposição orientava o controle da população por meios vinculados ao controle da natalidade. Não podemos esquecer que Malthus discutia com socialistas — ditos utópicos — sobre a "ajuda" contida na lei dos pobres, em vigor na Inglaterra desde a Idade Média. Ao longo do século XX, várias vezes esse tema foi retomado. Já no século XIX, Karl Marx — retomando ideias dos economistas clássicos, como David Ricardo por exemplo — deu um passo adiante e argumentou que a fome era causada pela distribuição desigual da riqueza e sua acumulação pelos capitalistas. A população depende da organização econômica e social. Os problemas de superpopulação e limites de recursos, enunciados por Malthus, são características inerentes e inevitáveis associadas ao sistema capitalista de produção.

THOMPSON (1929) e, posteriormente, NOTESTEIN (1945), referindo-se a um processo histórico de mudança que explica as tendências de nascimentos, mortes e crescimento populacional que ocorreram em sociedades industrializadas, especialmente as sociedades europeias, afirmam que a problemática das teorias populacionais trata a questão do controle da natalidade - quantidade de nascidos era o elemento político a ser controlado - , como forma de superação das desigualdades sociais.

Nos anos 1960, entretanto, com a intensificação do processo de urbanização e o controle da natalidade em países da Europa - com políticas de controle, que levaram à transição demográfica e lograram êxito no pós guerra - e o crescimento populacional dos países da América Latina e Ásia, o fenômeno metropolização, a periferização, as favelas, guetos e outras formas de segregação passam a serem vistas ainda na perspectiva das "classes perigosas", portanto o fenômeno demográfico ganha a leitura do fenômeno 
da multidão e deslocamentos analíticos passam a problematizar a política da morte, como forma de controle populacional. A política de morte adaptada pelo Estado é conhecida como necropolítica. MBEMBE (2003) questiona os limites da soberania quando o Estado escolhe quem deve viver e quem deve morrer. Essa abordagem emerge no seio das políticas de segurança pública, onde negros pobres, periferias, guetos e favelas tornam-se o centro de uma política de extermínio, em nome do inimigo (narcotráfico, o assaltante, a milícia) e assim justificam a violência institucional nas áreas dos pobres trabalhadores, homens, mulheres e crianças ficando nas miras das armas e tornando-se vítimas fáceis de "balas perdidas".

\section{O que esse debate tem a ver com a crise do coronavirus (SARS-CoV-2)?}

A crise societária é aquela em que "tudo que é sólido desmancha no ar", ou seja, o grau de incerteza ganha uma dimensão que não abala somente as estruturas econômicas, mas as estruturas políticas, éticas, culturais. A crise do coronavirus é pela sua natureza a crise do capitalismo no seu sentido mais profundo e, portanto, societário. O pensamento hegemônico certo da recessão e das altas taxas de mortalidade devido à COVID-19, atua no presente com a lógica da guerra. Nesse sentido, a disputa de narrativas sobre o que será produzido no futuro como Welfare State ou a exacerbação neoliberal está em curso e produzindo diversas guerras: a ideológica, a material, a disputa por território. E a problemática do reconhecimento da multidão, da população e, sobretudo dos pobres e das chamadas minorias ganha uma dimensão de desejo do controle que é fantasmagórico.

Essa dimensão fantasmagórica aparece devido ao grau de letalidade da COVID19, na população. Desse modo, a análise da realidade dos Estados Unidos, em que historicamente a população negra é segregada e têm-se uma sociedade em que os serviços de saúde são privados, nos oferece a possibilidade de observar uma sociedade em que os níveis de riqueza e pobreza diferem de outros lugares no mundo. A COVID-19, afirmam estudiosos (OLIVEIRA et. al, 2020) atingem com maior mortalidade os mais idosos, os com doenças crônicas como cardiopatias, diabetes, câncer, baixa imunidade. Mas, não somente esse grupo de risco vem sofrendo a letalidade, também os mais pobres estão sendo seriamente afetados. Em Chicago e Nova York faleceram milhares de pessoas 16 de abril de 2020, sendo que desses mortos, mais de $60 \%$ são negros e pobres, devido ao modelo de democracia em que a saúde é mercadoria e que os pobres não podem acessar o sistema de saúde. 
Vejamos as notícias:

Em Chicago, cidade mais populosa do estado de Illinois, onde o ex-presidente americano Barack Obama vive e fez carreira política e acadêmica, os negros compõem $30 \%$ da população, mas representavam $68 \%$ dos 118 mortos e $52 \%$ dos cerca de cinco mil casos confirmados no município até quarta-feira (7). A taxa local de morte de negros pela pandemia é quase seis vezes maior que a de brancos. (MARINI, 2020, p. 1)

E mais:

Em Milwalkee, município com a maior população de Wisconsin e a $28^{\mathrm{a}}$ dos EUA, o cenário é parecido. Os negros, que formam $28 \%$ da população, representam $73 \%$ das 45 mortes do município. A desproporção é mais alarmante quando se considera os índices de todo o estado: quase metade das mortes por coronavírus é de negros, que constituem apenas seis por cento da população. (MARINI, 2020, p. 2)

O reconhecimento da morte dos negros é fruto da demanda das reivindicações dos movimentos e grupos negros. Porque a estatística torna invisível as clivagens de classes e de renda. Mais uma vez como expressão de luta pela visibilidade, foram os movimentos negros dos Estados Unidos, apoiados pela prefeita de Chicago, Lori Lightfoot, que exigiram a divulgação dos dados como o corte racial.

Os formulários de controle americanos registram idade, sexo e também etnia dos notificados. Mas, por causa das diferenças de exigências legais entre os Estados, autoridades de vários deles optaram por não divulgar os números divididos por este quesito.

Grupos sociais de apoio e defesa dos negros reivindicam que todas as unidades da federação nos EUA publiquem os números e percentuais estratificados de afetados brancos, negros, hispânicos e asiáticos para reforçar, com dados, as ações de assistência e combate. (MARINI, 2020, p. 2)

Os "grupos sociais" reivindicam que os dados sejam mais específicos, desse modo modificando o lugar da luta social, impondo ao Estado que reconheça as diferenças e assume papel diferente de invisibilizar os afetados pela doença.

A prefeita de Chicago, Lori Lightfoot, que é negra, emitiu uma ordem de saúde pública exigindo que os hospitais divulguem dados compartilhados por etnia. "Esses números nos tiram o fôlego. O momento é de esforço da nação para o bem de todos, independentemente de condição social, origem e também etnia", resume ela.

Lori desconfia da existência de uma "subnotificação significativa" também entre os hispânicos, que representam $29 \%$ da população e $14 \%$ dos casos na cidade. Entre os asiáticos, sete por cento dos habitantes, a taxa de contágio é de 3,6\%.

Um branco vive em média 8,8 anos a mais do que um negro em Chicago. A taxa de diabetes entre a população negra é duas vezes maior, e o volume de mortes relacionadas a problemas pulmonares, $20 \%$ mais alto. Dois em cada cinco adultos negros da cidade (40\%) têm hipertensão, índice $25 \%$ maior que o dos brancos. (MARINI, 2020, p. 2) 


\section{$\bar{O}$ trabalho intelectual a serviço da necropolítica: o velho-novo no controle da população}

Toda crise torna-se um contexto rico de emergência de ideias. E essas ideias construídas pelas mídias e redes hegemônicas tendem a se fortalecer. O final da década de 2010 é marcado por emergência de governos com ideias fascistas, genocidas e que se afirmam em torno de discursos que antes eram vistos como eticamente perigosos. Uma afronta aos direitos humanos. A década de 2020 já nasce no contexto de agudização da crise econômica e da ampliação do desemprego a nível mundial. No Brasil, o modelo neoliberal produz discursos e políticas reformas na previdência e de estímulo ao pequeno empreendedor como solução da crise econômica do país. O advento do coronavírus fez com que as elites passem a sentir o medo na pele e por isso a expansão da política de isolamento social e assim se aproximando aos interesses das empresas, das mídias. Com ou sem o Isolamento o impacto na economia é certo como aponta Alves (2020). Afinal a COVID-19 vai aparecer primeiro em países desenvolvidos onde a população tem mais recursos, mas ela chegará a espaços onde a população tem menos recursos para enfrentar a pandemia. Diante dessa constatação as autoridades brasileiras, apontam que o problema social como a produção dos "bandidos" e milícias nas favelas e periferias, anunciam a tendência de grande mortalidade dos favelados pobres e negros.

Na literatura aparece a análise da necropolítica voltada ao contexto da violência institucionalizada nos corpos e nas favelas, guetos e periferias. A questão demográfica vem somar como discurso de transcendência, ou seja, de solução das desigualdades sociais.

Assim, de fato há um deslocamento do discurso que vinha desde o final do século XIX com ênfase no crescimento da população, sobretudo, os mais pobres. Esse crescimento da população tinha a origem em fenômenos, como a natalidade, a queda da mortalidade e o êxodo rural. Desse modo, historicamente, diante de processo de colonização baseado na mão de obra indígena e africana, a população trabalhadora vai se consolidando com base na necessidade dessa mão de obra, mas ao mesmo tempo o desejo de controle sobre os corpos e multidão. Isto ocorreu tanto no Brasil como nos Estados Unidos, incluindo nesse caso uma grande mão de obra pobre de origem latina. Em outra abordagem, a ênfase no debate está em relacionar o crescimento populacional a concentração urbano-metropolitana, concentração essa entendida como produtora de violência urbana, apontando a necessidade de controle e segurança pública. Nesse 
contexto os espaços dos pobres são criminalizados, estigmatizados e estereotipado. Essas características incidem sobre a população das periferias, favelas e guetos.

O contexto do coronavírus produz algumas mudanças importantes: primeiro, já sabemos que o modelo econômico hegemônico tem vários limites, uma delas é a política de concentração de renda e a política de estruturação da saúde pública, que sempre ocasionou problemas de acesso para aqueles que não tem condições de bancar saúde privada. Segundo refere-se ao controle social do discurso sanitarista. Nesse discurso sanitarista, o reconhecimento dos limites da infraestrutura de saúde e o fato de escolher quem vai cuidar de quem vai morrer. Desse modo, o pensamento mais conservador coloca-se contra o isolamento social e a quarentena porque seria melhor que todos pegassem o vírus ao mesmo tempo para ganhar a imunidade social. Por trás desse discurso, encontra-se o discurso demográfico de Walter Scheidel, como se observa a seguir:

Apesar do duro impacto humano e econômico da pandemia de coronavírus em todo o mundo, a perspectiva histórica aponta que o covid-19 tem o potencial de afetar positivamente o que é apontado como um dos maiores problemas do mundo atual: a desigualdade social.

Isso porque, ao longo da história, grandes epidemias tiveram efeito "nivelador" da economia, defende o historiador Walter Scheidel, professor da Universidade Stanford, nos Estados Unidos. O princípio visto ao longo da história é simples, ele explica em entrevista à BBC News Brasil: quando muita gente morre, há uma redução de mão de obra, então trabalhadores podem vender sua força de trabalho por salários mais altos, e as pessoas ricas passam a ter uma renda menor. (BUARQUE, 2020, p. 1)

O "princípio simples" é de que haverá maior oferta de trabalho e logo pode se concluir que a desigualdade social diminuirá, considerando, claro, a importância dos grandes eventos de epidemias e guerras na história. Diz no seu livro: "The Great Leveller: Violence and the History of Inequality from the Stone Age to the Twenty-First Century", obra que traça a história da desigualdade social no mundo e analisa as rupturas que levaram a sua diminuição. Sua narrativa sustenta o argumento de que grandes "disrupções" — tais como apontadas pelos "quatro cavaleiros do apocalipse" conseguiram reduzir a desigualdade econômica ao longo da história, tais como as grandes epidemias, falências do Estado, guerras.

E mais:

BBC News Brasil - Seu livro fala de pandemias como "niveladores", rupturas que diminuíram a desigualdade no mundo ao longo da história. Pode explicar como isso acontece?

Walter Scheidel - Isso está muito claro na história, especialmente até o século 20, quando o mundo era formado por sociedades agrárias. O princípio é muito simples: Se pessoas demais morrerem, vai haver uma redução de mão de obra, mas a quantidade de terra para o trabalho 
continua sendo a mesma, então o valor do trabalho sobe enquanto o valor da terra cai. Como resultado, trabalhadores podem vender sua força de trabalho por salários mais altos, e as pessoas ricas que são proprietárias de terra vão ter uma renda menor, pois a terra vai valer menos e vão ter que pagar salários mais altos.

É um mecanismo muito simples, mas que vemos se repetir ao longo da história até o século 20. É fácil ver ao longo da história como epidemias severas tinham um resultado positivo — se é que se pode dizer isso - em termo de empoderamento da classe trabalhadora e atrapalhando os interesses dos mais ricos. Isso não funciona mais exatamente assim porque não somos mais uma sociedade agrária. (BUARQUE, 2020, p. 2)

O tipo de raciocínio exposto acima, nos leva a crer que o conhecimento geográfico pouco combateu os discursos de morte e se preocupou em apresentar a população como estatística. Os métodos utilizados pela Geografia, para o tratamento do tema da população consistiram, por muito tempo, em quantificá-la, por isso devem ser questionados diante da pandemia de coronavírus. Abordá-la como elemento atuante que resiste ao poder (RAFFESTIN, 1993), é tarefa urgente no atual momento. Pois segundo Véron (1993), a demografia foi

Vítima do seu sucesso, cada vez mais solicitada, constrangida por uma forte expectativa social a exprimir opiniões numerosas e definitivas sobre temas delicados, a demografia sofre hoje frequentes vezes a tentação de ignorar a complexidade social".

Desse modo a demografia da contagem dos vivos e mortos não dará conta da complexidade social dos espaços em que está se desenvolvendo a luta pela sobrevivência. Mike Davis (2020) aponta três grandes desafios para os pesquisadores que querem caracterizar o surto, e o primeiro trata da questão dos números e suas fragilidades:

Primeiro, a falta permanente de kits de teste, especialmente nos Estados Unidos e África, tem impedido estimativas precisas de parâmetros chave, como a taxa de reprodução, tamanho da população infectada e número de infecções benignas. $\mathrm{O}$ resultado tem sido um caos numérico (DAVIS, 2020).

No Brasil o desafio citado, também é tema de debates e disputas políticas que desconsideram a população como atuante no processo de enfrentamento da pandemia. $\mathrm{O}$ ministro da saúde expôs em entrevista recente a criação de programa piloto em favela do Rio de Janeiro, apontando a necessidade de conversar com grupos aliados da morte, como o narcotráfico e as milícias — um portal de grande mídia noticiou em março: "Coronavírus: traficantes e milicianos impõem toque de recolher em comunidades do Rio”. Tal medida resulta em insegurança para comunidades que já enfrentam cotidianamente a falta das condições básicas de existência e o terror imposto por aqueles grupos. 
No caminho contrário seguem as associações em Paraisópolis (SP). A observação de notícias veiculadas em meios digitais são as seguintes: "Sem esperar ajuda do governo, Paraisópolis contrata médicos para combater vírus"; "Paraisópolis tenta proteger mais vulneráveis contra coronavírus e miséria”. Exemplos como esses se multiplicam e poderiam ilustrar esse texto. Desse modo, o que se espera é uma modificação na forma de abordagem e apresentação do tema da população, onde o humano não seja ofuscado por qualquer possibilidade técnica. Já não se pensa a população como números, mas como sujeito de ação que luta contra os "processos de desumanização e de industrialização da morte" (MBEMBE, 2018).

\section{Considerações Finais}

Em contexto de agudização de crises, emergem propostas de soluções que disputam o futuro. Os debates demográficos fazem parte desse rol de soluções de problemas. O século $\mathrm{XX}$ foi marcado pelas políticas de controle da natalidade e das teorias de transição demográfica. As necropolíticas emergem nesses contextos, quer seja nas ações fascistas e nazistas, nas guerras mundiais, conflitos nacionais e política de tolerância zero contra narcotráfico e nas ações de violência institucional do Estado. No contexto da Pandemia do coronavirus, as disputas discursivas ganham notoriedade e a questão demográfica aparece vinculada à alta letalidade do vírus e aos discursos de que a economia é mais importante que a vida. Afinal, a política da morte passa a ser publicizada para justificar soluções para a maior recessão pós 1930. O futuro está sendo disputado e mais uma vez os corpos e espaços pobres estão na mira da expansão das mortalidades (como afirmam as pesquisas futuristas, os dados do presente e as narrativas da epidemiologia) e, também na mira das políticas que estão mais preocupadas com o lucro e com a queda da riqueza das empresas. Assim, o presente ensaio é, sobretudo, uma reflexão do presente e, reflete a importância da Geografia para a compreensão do poder da ideologia na produção das leituras do mundo. A compreensão dos estudos sobre a população e a demografia ganha centralidade para compreendermos as estatísticas de vida e morte no tempo atual. 


\section{Referências}

BUARQUE, Daniel. Entrevista Coronavírus: Autor americano Walter Scheidel aponta potencial da covid19 para reduzir desigualdade no mundo. UOL. ECONOMIA, - São Paulo para a BBC News Brasil, 05/04/2020 07h26. Disponível: https://economia.uol.com.br/noticias/bbc/2020/04/05/coronavirus-autoramericano-aponta-potencial-da-covid-19-para-reduzir-desigualdade-no-

mundo.amp.htm\#aoh=15863845924231\&referrer=https\%3A\%2F\%2Fwww.google.com\&amp_tf=Fonte $\% 3 \mathrm{~A} \% 20 \% 251 \% 24 \mathrm{~s}$

DAVIS, Mike. A crise do coronavírus é um monstro alimentado pelo capitalismo. In: DAVIS, M. et al. Coronavírus e a luta de classes. Brasil: Terra sem amos, 2020.

ALVES, José Eustáquio Diniz. A pandemia de Coronavírus (Covid-19) e o pandemônio na economia internacional, artigo de, in EcoDebate, ISSN 2446-9394, 9/03/2020. Disponível em: https://www.ecodebate.com.br/2020/03/09/a-pandemia-de-coronavirus-covid-19-e-o-pandemonio-naeconomia-internacional-artigo-de-jose-eustaquio-diniz-alves/. Consulta: 26/04/2020.

MARINI, Eduardo. Negros sofrem muito mais do que brancos com a pandemia nos EUA: Proporções de contágio, doença e morte são bem maiores na população negra. Condições sociais e de assistência de saúde influem nos índices. R7: Internacional, 8/4/2020 às 14h05 (Atualizado em 8/4/2020 às 18h31). Disponível: https://noticias.r7.com/internacional/negros-sofrem-muito-mais-do-que-brancos-com-a-pandemia-noseua08042020?amp\#aoh=15863781136985\&referrer=https\%3A\%2F\%2Fwww.google.com\&amp_tf=Fonte\% $3 \mathrm{~A} \% 20 \% 251 \% 24 \mathrm{~s}$

MBEMBE, A. On the Postcolony. Berkeley e Los Angeles: University of California Press, 2001

MBEMBE, A. Crítica da razão negra. Durham: Duke University Press, 2017.

MBEMBE, A. e Goldberg, D. The Reason of Unreason: Achille Mbembe e David Theo Goldberg em uma conversa sobre Critical of Black Reason.2018

MBEMBE, A. Biopoder soberania, estado de exceção política da morte (original de 2003). Arte \& Ensaios | Revista do PPGAV/EBA/UFRJ | n. 32 | dezembro 2016

MBEMBE, A. Frantz Fanon e a política da visceralidade. Duke Franklin Humanities Institute, 2016.

MBEMBE, A. Future Knowledges and the Dilemmas of Decolonization Duke Franklin, Humanities Institute, 2017.

MBEMBE, A. Necropolítica. São Paulo, N-1 Edições, 2018.

MBEMBE,A.The idea of a borderless world: Africa is a Country. Institute de Humanidades Duke Franklin, 2018.

NOTESTEIN, Frank W. Class Differences in Fertility. Annals of the American Academy of Political and Social Science 188 1936: p. 26-36.

NOTESTEIN, Frank W. Some Implications of Population Change for Post-War Europe. Proceedings of the American Philosophical Society 87, no. 2 (August): 1943, p. 165-174.

NOTESTEIN, Frank W. Population-The Long View, In Food for the World, ed. Theodore W. Schultz. Chicago: University of Chicago Press, 1945.

NOTESTEIN, Frank W.Population Growth and Economic Development. Colombo. Reprinted in Population and Development (1964) -Review 9 (1983): p. 345-360.

NOTESTEIN, Frank W. (1967). The Population Crisis: Reasons for Hope. Foreign Affairs 46(1): 1967, p.167-180.

NOTESTEIN, Frank W. Demography in the United States: A Partial Account of the Development of the Field. Population and Development Review 8: 1982, p. 651-687. 
NOTESTEIN, Frank W. Economic problems of population change, in Proceedings of the Eighth International Conference of Agricultural Economists. London: Oxford University Press, 1953, p. 13-31.

OLIVEIRA, Wanderson Kleber de et. al. Como Brasil pode conter o COVID-19. Epidemiol. Serv. Saude, Brasília, 29(2):e2020044, 2020

RAFFESTIN, C. Por uma geografia do poder. São Paulo: Ática, 1993.

SANTOS, Milton. A natureza do Espaço: técnica e tempo, razão e emoção. São Paulo: HUCITEC, 1996, 308p.

SANTOS, Milton et. al. O papel ativo da Geografia: Manifesto. XII Encontro Nacional de Geógrafos, Florianópolis, Julho de 2000. 18p.

SANTOS, Milton Por uma outra Globalização: do pensamento único à consciência universal. Rio de Janeiro: Record, 2000b.

SCHEIDEL Walter, The Great Leveller: Violence and the History of Inequality from the Stone Age to the Twenty-First Century Princeton University Press, DOI: 10.2307 / j.ctv346rs7, 2017.

SEM esperar ajuda do governo...https://www.terra.com.br/noticias/brasil/especial-sem-esperar-ajuda-dogoverno-paraisopolis-contrata-medicos-para-combatervirus,e415c483833ab8a6eae30c8398a68080lf8les0r.html

THOMPSON, Warren S. Danger Spots in World Population. New York: Alfred A. Knopf, 1929.

THOMPSON, Warren S. "Population." American Journal of Sociology 34(6): 1929, p. 959-975.

THOMPSON, Warren S. Population Problems (5th edition, 1965) New York: McGraw Hill, 1930.

THOMPSON, Warren S. Population and Peace in the Pacific. Chicago: University of Chicago Press, 1946.

THOMPSON, Warren S. Plenty of People: The World's Population Pressures, Problems and Policies and How They Concern Us, Rev. edition. New York: Ronald Press, 1948

THOMPSON, Warren S. Population and Progress in the Far East. Chicago: University of Chicago Press, 1959.

THOMPSON, Warren S., and P. K. Whelpton. Estimates of Future Population of the United States, 19402000. Washington, D.C.: National Resources Planning Board, 1943.

THOMPSON, Warren S. Population Trends in the United States. New York: Gordon and Breach Science Publishers, [1933] 1969.

VÉRON, Jacques. Aritmética do homem: a demografia entre a ciência e a política. Lisboa: Instituto Piaget, 1993. 